\title{
TRICHOBEZOAR OF A SMALL INTESTINE IN A 10 YEAR OLD FEMALE Ievgen Mozhaiev ${ }^{1}$, Natalia Mozhaieva ${ }^{2}$, Yuliya Modna $^{3}$, Daniel Khashchuk $^{4}$
}

\begin{abstract}
The majority of items which accidentally enter the organism significantly threaten the health and life of a child. The problem of bezoars in the practice of pediatric surgeons and emergency pediatric surgery remains relevant, as evidenced by this clinical case. As a clinical picture of bezoars is diverse and this pathology is quite rare in childhood each case with a bezoar represents a practical interest for pediatric surgeons. This case is interesting because it describes a clinical case involving a bezoar of a child's small intestine with the clinical picture of an acute mechanical (obstructive) intestinal obstruction.
\end{abstract}

UDC Classification: 616.33/34;613.2;616.8-009.83; DOI: http://dx.doi.org/10.12955/cbup.v6.1282

Keywords: child, gastrointestinal tract, bezoar, enterotomy.

\section{Introduction}

Bezoars are a special kind of foreign body that form in the digestive tract, mainly in the stomach cavity, upon ingestion of various substances which form a foreign body (Sanders, 2004). This pathology is quite rare in childhood, and in this regard, doctors are practically not familiar enough with the given pathology (Antropova et al., 2015). Having seen many different bezoars, Sokolov and Davidov (2008) referred to other available sources and described 11 types of bezoars of the gastrointestinal tract depending on their composition (Pace and Fearne, 2003). The most commonly encountered in children are phyto- and trichobezoars (Khattala et al., 2008). Children may also come by piksobezoars after swallowing chewing gum or clay or the lactobezoars (composed of lactose and casein) which form in premature infants who are fed formula foods. There is also some data regarding mixobezoars in combination with developmental defects of the duodenum (congenital membrane or hyperfixation of the duodenum) due to an interruption of evacuation from the stomach (Dikicier et al., 2015). Phytobezoars, which make up 70-75\% of all bezoars, are dense, round or cylindrical masses whose center consists of residues of plant origin. More commonly, phytobezoars are made of sunflower seed shells and pits of fruits (persimmons, plums, grapes, figs, cherry, dates, sunflower seeds, nuts also). This type of bezoars is usually found in the stomach (78\%), and in the small intestine(15-16\%) (Anupama et al., 2013). Trichobezoars form when hair and wool enter the gastrointestinal tract, resulting in a dense felt-like mass with an admixture of mucus and food - the socalled "hair tumor" (Gonuguntla and Joshi, 2009). The clinical picture of bezoars is diverse. Each case represents a practical interest, which became the motive behind the publishing of our observation.

\section{Clinical case}

This case is interesting because we have not met the description of a clinical case involving a bezoar of a child's small intestine with the clinical picture of an acute mechanical (obstructive) intestinal obstruction.

Studies were conducted in accordance with the principles of the Declaration of Helsinki. The study protocol was accepted by the local ethics committee (LEC). Informed consent from the child's parents was obtained for the examination and treatment.

A child (born in 2007) was transferred to the pediatric surgical clinic of LSMU ("Luhansk State Medical University") in the city of Rubizhne from the city hospital's infectious department, where she stayed from February $8^{\text {th }}, 2017$ to February $9^{\text {th }}, 2017$ with complaints of nausea, repeated vomiting, general weakness and periodic spastic pains in the stomach which tended to increase.

From the history of the disease it is known that the child was ill from February $7^{\text {th }}$, 2017, when although appearing to be well she continued to experience repeated vomiting along with pain in the upper abdomen. EMS delivered the child to the infectious department where she was hospitalized and examined by another surgeon. Signs of an acute surgical pathology at the time of examination were not manifested. During the day the child was infused with a comprehensive antispasmodic and

\footnotetext{
${ }^{1}$ Luhansk State Medical University, Ukraine, mozhaevy@ukr.net

${ }^{2}$ Luhansk State Medical University, Ukraine, n.v.tereshenko@ukr.net

${ }^{3}$ Trinity School of Medicine/ Saint Vincent \& the Grenadines, ymodna@trinityschoolofmedicine.org

${ }^{4}$ Trinity Scool of Medicine/ Saint Vincent \& the Grenadines,dankhash@gmail.com
} 
detoxification therapy but the positive clinical effect was not achieved. Due to a lack of constructive dynamics, the child was re-examined by the supervisor of the hospital's surgical department and sent to the pediatric surgical clinic with the diagnosis of acute appendicitis. The child's general condition at the moment of hospitalization was severe due to progressive intoxication, also was noted pallor of the skin and mucous membranes; tachypnea: $26 \mathrm{bpm}$; tachycardia: $122 \mathrm{bpm}$; low-grade fever: $37.5^{\circ} \mathrm{C}$; hard breathing was auscultated over all lung fields bilaterally; cardiac activity was rhythmic with clear heart tones; the abdomen was its usual form, sunken in the umbilical and hypogastric regions; soft to palpation with a sharp pain in the epigastric region. Symptoms of peritoneal irritation were absent. Clinically there was peritonism. Intestinal peristalsis was strengthened, pathological noises were not auscultated. According to the child's mother, stool came out on February 8, 2016 after an enema, but the gases did not go away. Diuresis via the urethral catheter was reduced. In the general analysis of blood: $\mathrm{Hb} 123 \mathrm{~g} / \mathrm{L}$; RBC $3.91 \times 10^{12} / \mathrm{L}$; WBC count $10.4 \times 10^{9} / \mathrm{L}$ (segmented $62 \%$, band form $4 \%$, lymphocytes $24 \%$, monocytes $5 \%$, eosinophils $5 \%$ ); platelet count $268 \times 10^{9} / \mathrm{L}$; Hct $38 \%$; ESR 5 $\mathrm{mm} / \mathrm{h}$. Clotting time $4: 18-4: 30$. Blood glucose $5.6 \mathrm{mmol} / \mathrm{L}$. The biochemical profile of the blood is as follows: total protein $63.8 \mathrm{~g} / \mathrm{L}$; urea $3.8 \mu \mathrm{mol} / \mathrm{L}$; creatinine $37.0 \mu \mathrm{mol} / \mathrm{L}$; total bilirubin $11.7 \mu \mathrm{mol} / \mathrm{L}$; directly conjugated $2.0 \mu \mathrm{mol} / \mathrm{L}$; indirectly conjugated $9.7 \mu \mathrm{mol} / \mathrm{L}$; aminotransferases: ALT $43.2 \mathrm{U} / \mathrm{L}$ $(\mathrm{N}<39 \mathrm{U} / \mathrm{L})$, AST $48.5 \mathrm{U} / \mathrm{L}(\mathrm{N}<47 \mathrm{U} / \mathrm{L})$; timolol test 0.6 units; blood alpha-amylase $26.6 \mathrm{mg} / \mathrm{hr} / \mathrm{mL}$; serum electrolytes: $\mathrm{K}^{+} 4.4 \mathrm{mmol} / \mathrm{L} ; \mathrm{Na}^{+} 138 \mathrm{mmol} / \mathrm{L} ; \mathrm{Ca}^{2+} 2.3 \mathrm{mmol} / \mathrm{L} ; \mathrm{Cl}^{-} 98 \mathrm{mmol} / \mathrm{L}$; osmolarity $203.4 \mathrm{mOsm} / \mathrm{L}$. In the general analysis of urine: light-yellow color, transparent; specific weight 1031; pH 5.0; protein $0.003 \%$; glucose not detected; ketone 3+; RBCs not detected; WBCs 3-4 per hpf; singular epithelial cells per hpf; homogenous mucus; salt and bacteria not detected.

The following instrumental methods were carried out with the interpretation of the received results.

Review of the X-ray of the abdominal cavity with the description: free gas in the abdominal cavity is not detected, though Kloyber's cups near the upper edge of the abdominal cavity are noted. Conclusion: dynamic obstruction? Description of the ultrasound of the abdominal organs: liver, gallbladder and pancreas are not visualized due to the presence of overdistended and peristalsing intestinal loops, while anechoic content is visualized in the lumen of the intestine with elements of increased echogenicity. Conclusion: high intestinal obstruction? Considering the negative clinical picture of high intestinal obstruction on the background of complex intensive therapy, the surgical procedure was conducted due to a poor clinical prognosis.

Surgical procedure: Under general anesthesia, an upper midline laparotomy was performed. During inspection of the abdominal cavity, the small intestine was sharply enlarged $15 \mathrm{~cm}$ distal to the ligament of Treitz due to the presence of a foreign body (Figure 1) in the lumen of the small intestine. The mobilization of the foreign body was impossible due to the density (Figure 2).

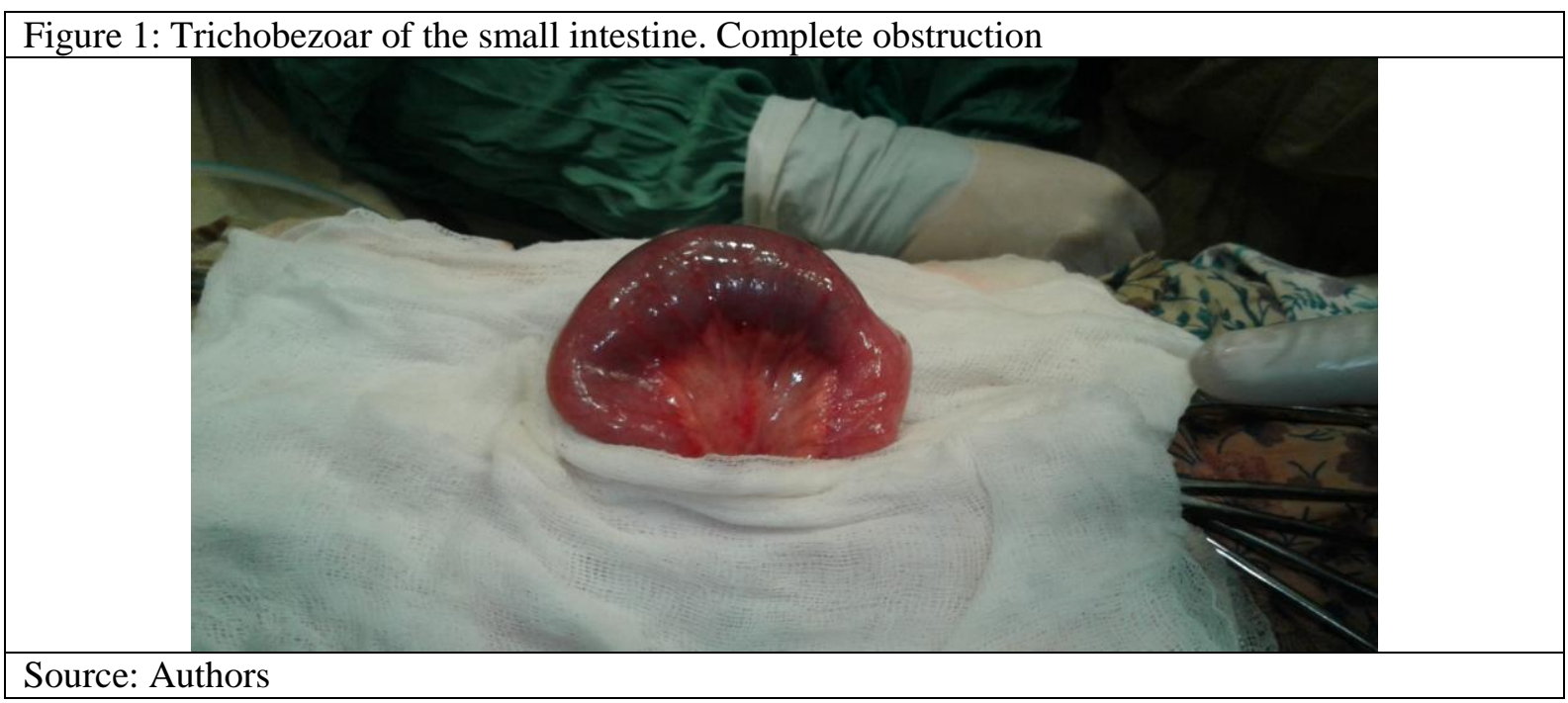

The transverse enterotomy was performed with a slanting cut towards the antemesenteric border along the lower pole of the bezoar and the trichobezoar was removed. Small intestinal defect was closed with single layered interrupted sutures. Nasointestinal intubation of the small intestine was also 
performed. The postsurgical period proceeded without complications. In the first day of the postsurgical period, was extubated and fractional enteral nutrition was started via tubing. On the fifth postoperative day, the nasointestinal tube was removed. On the fifteenth postoperative day, the child was discharged.



\section{Discussion}

Trichobezoars are the second most common group of bezoars, most commonly associated with the trichotillomania (urge to pull out one's hair) and trichophagia (urge to eat one's hair) (Khattala et al., 2008). Trichobezoars are diagnosed preferentially in adolescent females and very rarely in young male and children (Jain et al., 2011). This group of bezoars usually develops in the stomach and characterized by late onset and lack of specificity leading to the late diagnosis, which is initiated by acute abdominal symptoms. The common symptoms of trichobezoars: nausea, vomiting, constipation, and body weight loss (Gonuguntla and Joshi, 2009). The patients with trichobezoars often have some complications, such as obstructive jaundice, intestinal intussusception, stomach dilatation, and gastric ulceration (Jain et al., 2011). Computed tomography is the best tool in the diagnostics of trichobezoars as there is a high possibility that a bezoar would not be visualized by an ultrasound scan (Pace and Fearne, 2003). Treatment options depend on the size and the location of the bezoar. Small bezoars may be removed by chemical dissolution or endoscopic techniques. Large bezoars may be only removed by surgical resection (Anupama et al., 2013). A multidisciplinary approach and counseling by a psychiatrist are essential to prevent recurrence of the trichobezoars because many of these patients have psychiatric disorders, family issues, and emotional problems (Jain et al., 2011).

\section{Conclusion}

The problem of bezoars in the practice of pediatric surgeons and emergency pediatric surgery remains relevant, as evidenced by this clinical case. The low frequency of this pathology among the general morbidity and the absence of pathognomonic clinical symptoms can lead to later diagnosis of the disease, resulting in the choice of false therapeutic tactics, which significantly increases the risk of further development of undesirable and life-threatening complications in children.

\section{References}

Antropova, E., Lavpukova, O., \& Ziginova, T. (2015). Redkiy sluchay oslozhneniya bezoara zheludochno-kishechnogo trakta [A rare case of complications of a bezoar in the gastrointestinal tract]. Retrieved September 19, 2018, from http://www.science-education.ru/ru/article/view?id=18131

Anupama, P., Sreekar, P., \& Bharati, H. (2013). Phytobezoar: A Rare Cause of Small Bowel Obstruction. Journal of Clinical \& Diagnostic Research, 7(10), 2298-2299.

Dikicier, E., Altintoprak, F., Ozkan, O., Yagmurkaya, O., \& Uzunoglu M. (2015). Intestinal obstruction due to phytobezoars: An update. World Journal of Clinical Cases, 3(8), 721-726

Gonuguntla, V., \& Joshi, D. (2009). Rapunzel syndrome: a comprehensive review of an unusual case of trichobezoar. Clinical Medical Research, 7(3), 99-102. 
Jain, M., Solanki, S., \& Bhatnagar, A. (2011) . An unusual case report of rapunzel syndrome trichobezoar in a 3-year-old boy. International Journal of Trichology, 3(2), 102-104.

Khattala, K., Boujraf, S., \& Rami, M. (2008). Trichobezoar with small bowel obstruction in children: two cases report. African Journal of Pediatric Surgery, 5(1), 48-51.

Pace, A. M., \& Fearne, C. (2003). Trichobezoar in a 13 year old Male: A case report and review of literature. Malta Medical Journal,1, 39.

Sanders, M. (2004). Bezoars: from mystical charms to medical and nutritional management. Practical Gastroenterology, 28 , $37-50$.

Sokolov, U. U., \& Davidov, M. (2008). Bezoary zheludochno-kishechnogo trakta u detey [Bezoars of the gastrointestinal tract in children]. Retrieved September 19, 2018, from https://cyberleninka.ru/article/v/bezoary-zheludochno-kishechnogotrakta-u-detey 